\title{
Rooms: Domesticated Landscapes and Urban Appropriations in the UAE
}

\author{
JUAN ROLDAN MARTIN \\ American University of Sharjah
}

This paper explores how certain exterior (not strictly defined as public space) conditions of the UAE are occupied by migrant groups of populations in order to establish a sense of belonging through sport activities.

These social rituals become an extension of their social/ private lives into the public through different tactics of appropriation of the city. The paper will focus on a specific terrain vague in Sharjah where we can find a vacant plot of land of around $5 \mathrm{~km} 2$; a former military plot of land that used to be a helicopters training field that now has become a hectic set of 32 cricket grounds. The difference with other improvised cricket grounds in the UAE is that this one is now legally available for migrant population through a complex self-managed leasing formula between Emirati land owners and Indian and Pakistani business men .

This new urban landscape is managed by the users themselves, shaping a new public realm, where self-made landscape, infrastructure and architecture create the right conditions for gathering, sharing and establishing a sense of community among peers.

"Everyday space (Urbanism) can be spirited, spontaneous, vital, and inclusive; all too often it is neglected by its inhabitants, ignored by city planners, and disregarded by critics."

-Everyday Urbanism, 1999

\section{INTRODUCTION}

It is always difficult to understand and to define a city. It is even more difficult to grasp its intrinsic behaviour and future growth. It's even more challenging to define the ones in the Middle East: those ones that have grown and sprawled at such fast pace over the last three decades. Their rapid evolution, and sometimes uncontrolled has been over criticised due to their excess, lack of planification and disregard for the pedestrian. Nascent cities, which in less than 50-year-old, have collected the tallest building and the biggest mall in the world, establishing new commercial and economic hubs where some years ago there was only sand dunes reaching the seashore. At the same time, these cities offer themselves as a great laboratory to understand the emergence and evolution of a nascent city almost from scratch.

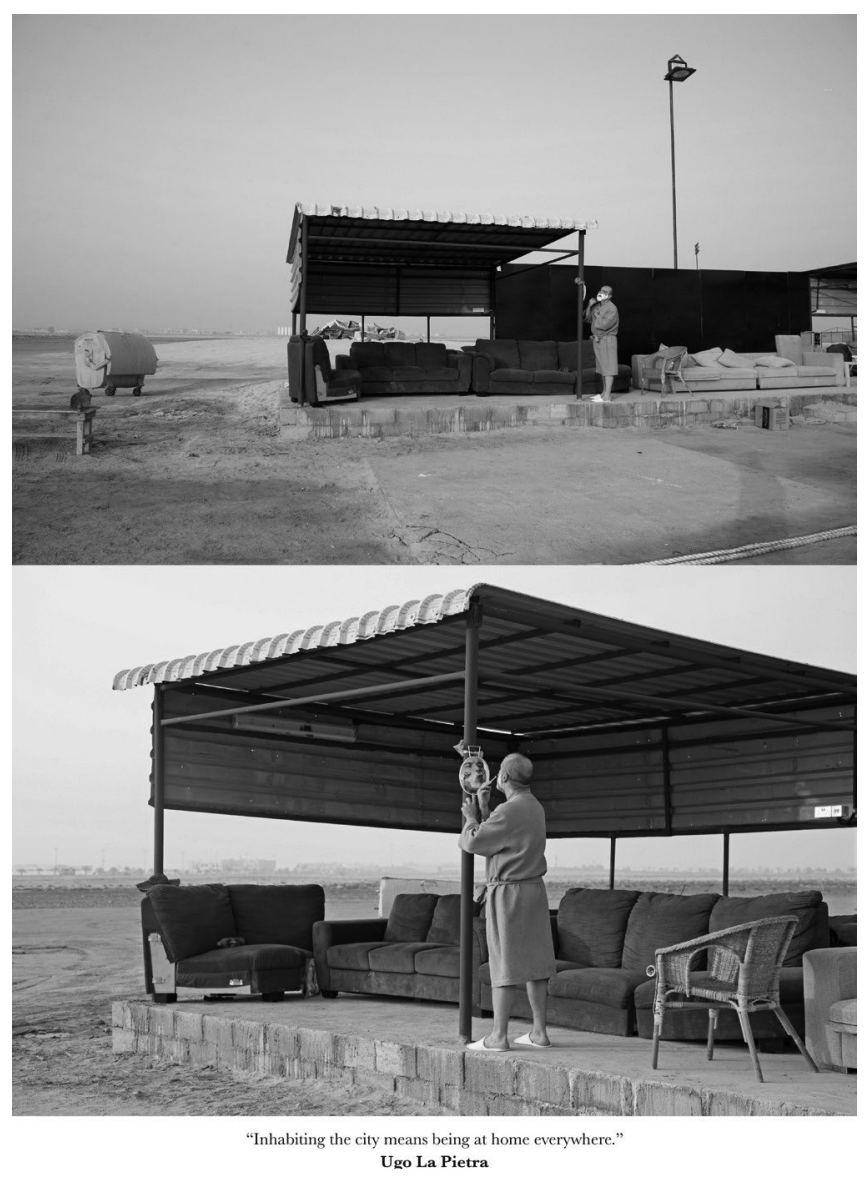

Figure 1: Rooms. Urban Inhabitation. Tactical re-appropriations of the city.

Reviewing the way cities have been analysed throughout architectural history, we can detect a common approach to its understanding: mainly as a construct made out of the different elements within the built environment: architecture, infrastructure and public space (the in-between). Therefore, we encounter the problem of understanding the other city: the transient, the invisible, the wake of activities which cannot be traced through a map.

In this sense, several authors have tried to reveal the intangible aspects of the cities from different perspectives.

Gordon Cullen, in his book The Concise Townscape (1974), becomes one of the first examples on how a new phenomenologist perception of the city can be achieved by using new parameters of visual evaluation in order to assess the 
compositional values of the city. The city, therefore, becomes the stage of a visual analysis in motion, beyond its static built environment.

It's probably Aldo Rossi (Rossi, 1966) who begins a philosophical and political detachment from the mere analysis of the urban form by introducing the concept (and distinction) of architecture and type. Rossi is also one of the first authors who considers the built environment from a social perspective as he introduces the "collective memory" as a primary form-making element for the city.

More recent theories like Everyday Urbanism (2008), have an embedded acknowledgement of how "a diffuse landscape of banal, repetitive and 'non-design' locations" is also an important element of the creation of the city ${ }^{1}$. It is important to note how this Everyday Urbanism (and their spaces) was first studied among migrant groups in U.S., where appropriations of the city happen -as social rituals- in certain areas of the city on a weekly basis, which is also part of our case study.

But, how can we compare the European post-industrial and modern cities with our subject of research in the Middle East? Can mid-twenty century theories answer the questions of young cities as Dubai or Sharjah -where time has not been able to leave enough marks and scars, where the patina of each brand-new monument is still fresh? ${ }^{2}$

We can indeed establish that comparison but certainly only in common elements and areas like their voids and their edges, where the city is yet to be built and where a clear tabula rasa condition exists. Areas, in and on the limit/edges of the city, where there is a lack of conflict between old versus new or heritage versus new architecture. It's within these kinds of terrain vague where we will be focusing this urban discussion.

The UAE and its emirates, as other urban cities, can be studied as the product of the functional systems that generate its architecture, and therefore of urban spaces, and as a spatial structure. Indeed, these cities go beyond urban designs that host building environments, since they are also a recollection of human behaviours that assist on reshaping spaces lodged with history and cultural meaning. Every building, alley, empty land -space-, is a place that carries intentions more or less noble, more or less conscious, and more less aesthetically expressed. These inanimate spaces are the scenarios that give life to the memory of the city, within these structures come the knowledge of the city. These spaces are the ones that we consider relevant, as they become instruments of social discourse for inhabitants in the $\mathrm{UAE}^{3}$.

This paper, therefore, will try to understand certain ephemeral activities (sport practices like cricket games) within these edges of the city, as they are repeated over time on the same spot and context, end up becoming the most permanent elements of its social structures without the mediation of designer nor architects.

The paper will also try to understand how these urban rituals, which gather groups of migrant populations in a weekly basis ${ }^{4}$ are a driving architectural element form the urban design perspective introducing some elements from the interior design discipline like domesticity and privacy.

These wild pet architectures ${ }^{5}$, create whether temporary activities around them (ephemeral, whether they can leave real traces and marks (permanent interventions) likes selfconstructed cricket pitches within the public realm.

\section{CONTEXT. SHARJAH AS BUILT ENVIRONMENT}

Defining this new urban dimension, or to adequately discuss it, has needed extensive research and in this case, we will limit ourselves to specific aspects that we believe enter into the consideration of the subject: how these new-born cities, offer the possibilities -thanks to their open edges- of making and completing the (already) built environments through processes of urban appropriation trough sport activities. The paper tries to unveil how these strategies of urban squatting offer the possibility of becoming living rooms within the public realm or as the title says: how certain activities, which due to certain space limitations in the domestic and interior realm, have the need of happening within an exterior condition: transforming certain urban conditions into domesticated landscapes.

To understand the built environment in the context of the UAE and more specifically in Sharjah, we first need to know some facts regarding the first settlement of Bedouin tribes in parallel to the Al Khalij coast, where the first souq was built as a mean of starting a centre of trading within the region ${ }^{6}$ in parallel to the port. This first settlement was first drawn and described as part of a nautical chart in $1703^{7}$, although there is a previous reference of a place named Sarcoa in a map by Ptolemy (2nd century AD).

This first Sharjah is defined by both physical factors: first the port (sahil) and its parallel souk the defensive wall with the Al Hisn fort. This first limit of this first settlement protecting the port from possible attacks from the desert.

Between these two elements we can find the residential area of traditional courtyard houses, which despite being an Arab settlement within the Islamic urbanism, seems to have a very different footprint growth and sprawl in comparison with the traditional dense "madinas" of cities in the region and in the Maghre $b^{8}$ area.

The second strategic sprawl of Sharjah happens after signing an agreement with the British Imperial Airways ${ }^{9}$. The public aero transportation company form U.K. needed a runway 
in the region as a strategic stopover for the flights to India as Saudi Arabia and Persia were not pleased to help and assist; after several failed negotiations with Dubai and Ras Al Khaimah it's Sharjah the one that will get to an agreement with Britain in July 1932, offering a strip of land to build the first international airport in the UAE.

The discovery of oil in the region and the oil revenues shared among all emirates from its foundation $\left(2^{\text {nd }}\right.$ December 1972), had an important turning point in the urban pacification of Sharjah.

The old courtyard houses entered then a phase of disregarding which lasted several decades. Families moved to isolated villas in the outskirts of the city between the old town and the new Sharjah international airport ${ }^{10}$ to the East (towards the desert), advancing the future growth of the city towards the desert, forgetting the port, the souq and the sikkas by the sea, and with the aim of becoming an international passenger's airport and nowadays the third largest airfreight hub in the Middle East ${ }^{11}$

It's within this sparse and porous part of the city (heritage area of Sharjah) where we can find some of the tendencies of the actual and contemporary behaviour of the city. In parallel to the opening of the Sharjah Art Biennial 11 (organized by the Sharjah Art Foundation SAF) in 2013, five new spaces were opened: the art spaces. These buildings take advantage of the pre-existing courtyard houses in the area, rebuilding the remaining masonry stone walls and completing their footprints with pristine white volumes. The contemporary take on this work of restoration is simple: the former courtyards (private) are now open, making a more porous urban fabric and creating a seamless transition between these new spaces and the rest of the city. This way, the open public space becomes part of this new concept of museum ${ }^{12}$ : the streets or sikkas and the open courtyards can host events, exhibitions, installations and performances. The open-air spaces have equal importance as the interior spaces of the museum. This is, in essence, a primary strategic element for the construction and future extension of the SAF spaces: we are not talking about a single museum or container. The institutions open ups their contents and activities onto the public realm (open-air Mirage cinema i.e.), creating rooms (indoor or outdoor) as a long-run strategy where the growth happens by restoring or occupying other vacant elements of the city ${ }^{13}$.

\section{SHARJAH: OPEN CITY AND A-FUNCTIONAL DESIGN ${ }^{14}$}

When the architect and artist Ugo La Pietra first showed his film "Interventi Publici per la Cittá de Milano," he was doing more than an outrageous performance placing a bed for him to sleep in the middle of the street. He was in fact, shouting out loud the motto of most of his work: "Abitare è essere ovunque a casa propria": Inhabiting is feeling at home everywhere. This bed surrounded by six bollards became the manifesto on his work on public interventions within the city of Milan. La Pietra claims, through these experimental tactics, new models of social urban relationships, subverting traditional customs, creating mechanisms of exchange between individuals and the city and vice versa.

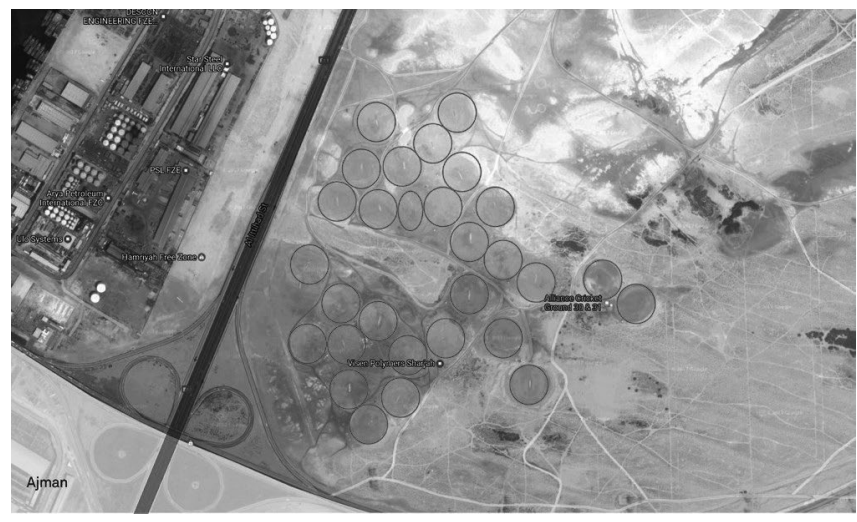

Figure 2: Former helicopter training fields in Hamriyah area, now occupied by cricket grounds

La Pietra's work revolts around the idea of the understanding of the un-regulated city, the Open City defined by Richard Sennet, where the different and opposite elements of the city clash and it's where in fact the unexpected happens.

Using photographic surveys and conducting interviews as main research and data collection means over the last four years, we can now shed some light about how certain behaviour of migrant population -unperceived or disregarded by the UEA population in general due to its illegal nature- establishes relationships with the land through strategies of urban appropriation. This paper will try to understand certain sport activities (mainly cricket games) happening in the vacant spaces of the cities all throughout the UAE as a way of placemaking and taking the theory a little bit further: how these rituals and their actors make and build the real city.

La Pietra's work and our conducted analysis within the area of Hamriyah helps us to understand how the city is used and appropriated by the unsolicited designers and the unexpected users (Roldan, 2013). This analysis and de-codification is the methodology deployed to understand how the city is occupied and the landscape is domesticated. These invisible rituals have codes, essential protocols to understand new ways of appropriation of the city, liturgies which create the inalienable sense of belonging of any citizen on the inhabited land.

\section{LIMINAL CITY AND URBAN INTERIORS. HAMRIYAH AREA, SHARJAH}

"It may be argued that conventional concepts of interiority and exteriority, public and private, are of little use in describing the formal, spatial and social character of the 


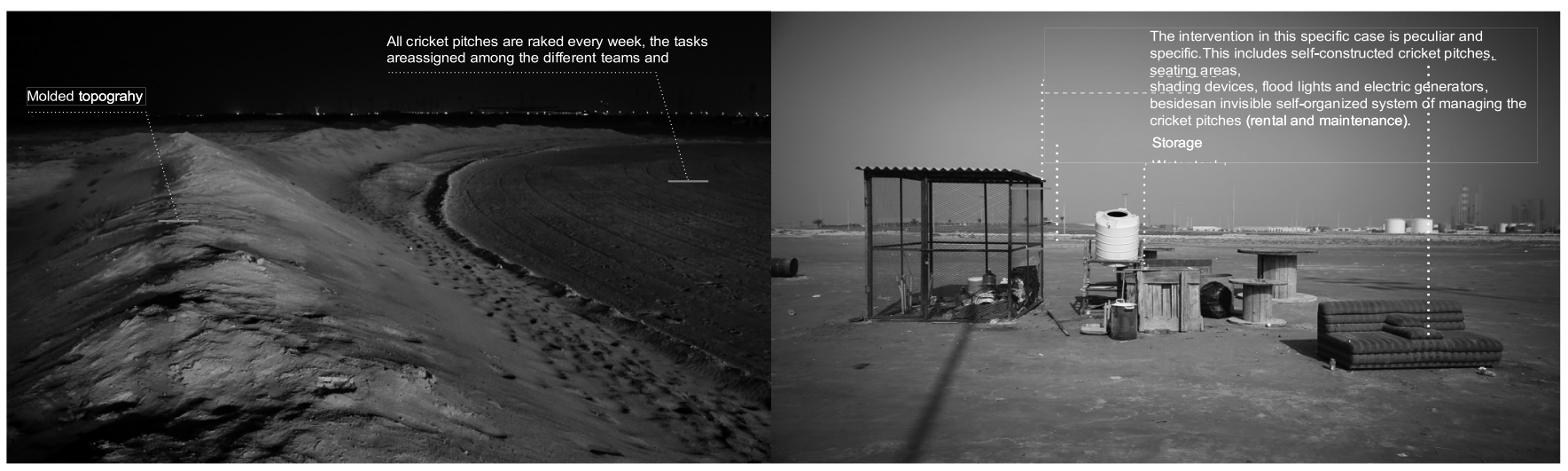

Figure 3. Domesticated landscape. Hamrijah cricket area. The topography is molded to accomodate the sport rituals even during night time.

late-modern megalopolis. In this proposition, to suggest a strict division between urban and interior design has become a problematic as drawing a line between built forma and landscape, between city and the nature."

-Joanna Merwood-Salisbury and Vanessa Coxhead. Exterior Interiors: the urban living room and beyond. Interiors Beyond Architecture, Wiley 2018

These liminal spaces offer different levels of interpretation and intervention by the users according to the different consensus established in the area with the different involved parts: the physical limitations of an urban (liminal) void, conflict among different (and possibly overlapping) activities and the tacit agreements which get generated during the whole process among different social groups and institutions ${ }^{15}$. According to its level intervention we can find from temporary to more permanent appropriations of the public space through construction or occupation. From the point of view of their scale we can find small scale interventions on a wall to territorial occupation of the landscape.

All of them have the same goal: to establish a link to the land through different communal practices, taming the environment, creating a sense of belonging through the domestication of the liminal space.

According to the definition of liminal space -as a blurred edge of the city-, we can find interior edges ${ }^{16}$ (in unbuilt or non-defined areas) and external edges (where the city meets the desert).

The most interesting fact in these interventions has to do with a higher level of (physical) conflict within the public realm as these practices happen in the limits of private properties in residential areas. When practiced in areas like Al Qasba in Sharjah, tacit agreements between different groups of users begin to happen; this means that drivers who park their cars in the central area of the parking lot will park their cars further away on Thursday night in order to allow enough room so the cricket match can happen during the following night and morning.

We will now focus our attention on a specific terrain vague in Sharjah, where we can find a vacant plot of land of around 5 $\mathrm{m}^{2}$; a former military plot of land that used to be a helicopters training field that now has become a hectic set of 32 cricket grounds. The difference with other improvised cricket grounds in the UAE is that this one is now legally available for migrants (India, Pakistan, Bangladesh and Sri Lanka mainly) through a complex self-managed leasing formula between Emirati land owners and Indian and Pakistani business men $^{17}$.

This $h$ urban landscape is managed by the users themselves, shaping a new landscape (cricket pitches and circular limits), maintaining their surfaces by raking them every week or installing seating areas, light floods or light architectural elements.

This paper studies how many of these exterior conditions (not strictly defined as public space) of the UAE, is occupied by migrant groups in order to establish a sense of belonging and as a way to extend their social private activities into the public realm due to a lack of intimacy within their own dwellings, and how these activities require specific spaces and architecture in order to achieve these interior conditions.

This sense of Interiority ${ }^{18}$ (Sennet) or how these strategies of Urban Interior Design (Hermida, 2012) ${ }^{19}$ become new urban tactics of city appropriation, have a direct link to interior design disciplines without the mediation of architecture as a mean of analysis, social participation or creation of new (designed) urban conditions.

Digging into one of the first graphic and phenomenological definitions of architecture we find Marc Antoine Laugier ${ }^{20}$, who defined the primitive hut in his Essay on Architecture (1753) not just as a first piece of architecture but as the process of creating an interior space, protected from the environment. 


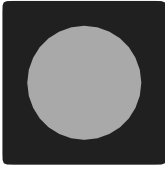

Interiors

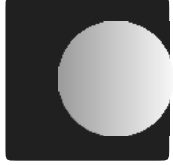

Interior POPS (Privately Owned Public Space). Cafeteria in a building's Cafeteria

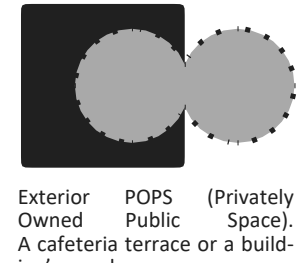

A cafeteria terrace or apuild ing's arcade
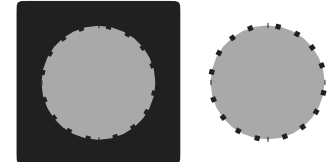

Hyper-interiors. Square, plaza

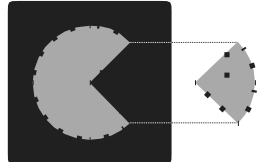

Hyper-interiors. Outdoor rooms in the UAE, where a portion of in the UAE, where a portion of extended into the public realm

Figure 4: Interiors versus POPS verus Hyper-Interiors versus Rooms

"...but enjoying the gift of nature; he lacks nothing, he does not wish for anything. But soon the scorching heat of the sun forces him to look for shelter. A nearby forest draws him to its cooling shade; he runs to find refuge in its depth, and there he is content."

- Laugier 1753

Architecture came later as a way of providing a formal enclosure, first of all the first elements that define an interior space were introduced: domesticity and privacy. As Georges Perec would suggest on interiors, these are spaces defined by actions, somehow "a room is a fairly malleable space" (Perec, 2008:28).

As recent research and writings claim Interior Design as an independent body of knowledge ${ }^{21}$, we can therefore think about these type of spaces as outdoor rooms or hyper-interiors.

We can consider these hyper-interiors as an endemic re-appropriation of the urban landscape within the Arabian Peninsula due to the following process:

- The lack of privacy within labor camps creates a need of extending social activities into the public (vacant) areas of the city

- The lack of public space, activates a need of appropriation of the vacant spaces by these unexpected users and unsolicited designers of the liminal city.

Therefore, we can consider that the lack of domesticity within the dwelled spaces of migrant people ( $85 \%$ of the population) activates mechanism of domestication of the vacant areas, extending these social practices into the public realm, accommodating sport activities and furnishing this new (outdoor) rooms accordingly.

These rituals of appropriation and self-construction reveals the un-seen, the hidden and sometimes illegal actions that in a transient manner, builds within the voids of the city and molds its topography to accommodate new and required functions.

\section{CONCLUSIONS}

"We move away from an architecture of frame and infill to an architecture of fixed spaces, boundaries, edges and thresholds, with items of furniture to define immediate functionality (loft in New York built in the early XX century). This type of architecture is, in principle, similar to both the highly-designed architecture and vernacular architecture of the past. We must think about architecture as providing a landscape for transient occupation (Braitenberg, 1986)."

-Stephen Gage, A suggested model for a-functional architecture 2012

A theory of Everyday Urbanism can help us to understand the generation of these casual settlements, almost as a contemporary definition of Architecture without Architects (Rudofsky, 1964) where the migrant population itself becomes a generator of not just a Social Space (Lefebvre, 1974). These two ingredients which generate opportunities of place-making within the vacant landscape of the city (inner and outer edges) are the key elements to define them as a real Instant City ${ }^{22}$ (Archigram).

This Instant City, is the one that descends -on a weekly basis- to activate the sleeping town through commerce and exchange, filling the liminal built environment with its objects and rituals.

Although it could be understood as a piece of temporary city. This is the part of the city that remains, reconfiguring its activities and footprint according to an ever-changing and shifting city planning. An Instant-Interior-City at the end of the day.

This way, we could use an expanded notion of Interior Design, which can be pulled out into the public realm, into the unfinished city. As a counterpart, Interior design can learn from the unfinished city, the a-functional (Gage, 2016) and the opencity scheme (Sennet, 2015).

Bearing in mind these characteristics and returning to our deployable tent structure, we can conclude that they share most of their core values, formal aspects and temporality. The only differences would be, in our case:

The consistency and repetition of the act or event by deploying a sport activity every Friday morning. 
These new spaces become an extension of the interiors which the players dwell, becoming an extension of certain rituals due to the lack of intimacy and domesticity.

These vacant spaces become, somehow, a new domesticated landscape through these "rituals of belonging" as a way of appropriating the city.

This is the part of the city hidden to the eyes of Giambattista Nolli or Bernard Rudofsky, but it is the real city made by the people for the people. Creating cities without architects.

\section{ENDNOTES}

1. Margaret Crawford, John Chase, and John Kaliski. Everyday Urbanism. (New York: Monacelli Press, 2008)

2. The dichotomy between analysis (pre-existent) and project (new) explained by Rossi in the introduction to the second edition of The Architecture of The City is a common element among urban studies in western cities: the interpretation of the ruin in order to understand a coherent answer with the architectural perspective, is the one that deals with this dichotomy and is one of the strongest philosophical school / courses within Italian Schools of Architecture.

3. As discussed with the project Nomadic Shadow (Itzel Cruz, Juan Roldan and Malak El Guel) as part of the exhibition Design, Change and Someone Else.
Curators: Moebius Studio. Organized by Maraya Art Center (Sharjah) 2016

4. Some of the interviewed groups of migrant populations have been gathering in the same spot or parking lot, in Sharjah industrial areas, over the ing in the same
last 15 years.

5. Borrowing the term Pet Architecture from the homonymous book by Atelier Bow Bow published in 2002.

6. It's worth mentioning that Sharjah is the only emirate with ports in boths coast line of the UAE: the West coast in the Arabian gulf known (Al Khalij) and in the Indian Ocean (Khor Fakkan area)

7. "The oldest modern map reference to Sharjah is on a nautical chart in the first edition of Thornton's'English Pilot' in 1703 " where it appears as 'Sharedje'. Source: Rab, Samia. Sharjah: Seascape Urbanism in a Khaliji Port City

8. Translated as "the West," eastern area of North Africa, which comprises Morroco, Libia, Mauritania, Lybia and Tunisia. It's considered to be the Berber Morroco, Libia,

9. A crucial enterprise launched in 1923 by the British empire in order to facilitate the transportation among the different colonies -and Trucial States in this specific case-, of the Commonwealth of Nations.

10. Sharjah International airport started operations in 1977.

11. According to official 2015 statistics from Airports Council International

12. http://www.aci.aero/Data-Centre/Monthly-Traffic-Data/ International-Freight-Traffic/Monthly

13. The architecture of these new art spaces was designed by the architect Mona El Mousfy, see: https://universes.art/en/sharjah-biennial/2013/ new-saf-art-spaces/

14. Sharjah Art Foundation (SAF) spaces is made up by the main Art Spaces (Heritage Area), the open-air cinema but also the "satellite" spaces all over Sharjah (city and emirate), like the Flying Saucer exhibition space in Sharjah (a former gas station and diner), the old ice factory in Kalba, the Hamriyah artists in residence and art space in Hamriyah beach and the recent perma-
nent installation the Rain Room in Al Mujarrah park area.

15. “...An example of the former might be the experience of a specifically designed restaurant, where the space, lighting, furniture, table setting, service and menu are designed together to make a memorable event. An example of the latter is the experience of a temple, for example, the Pantheon stands in awe and wonder." Stephen Gage, 2012

16. In many cases the term Public Space (vacant urban realm in western countries) is difficult to define in UAE, as the land always belongs to rulers or public entities.

17. Sennet, Richard. The Edge: borders and boundaries. Sennet believes in the idea of open edges, with porosity and capacity od exchange as one of the main features of the open city system.
18. These migrant business men then sublet the grounds to cricket teams for a low fee (around 40 EAD per person per match). The businessmen support migrant population, get publicity as these matches are widely promoted on social media and in exchange player maintain the grounds.

19. "I am interested in the relationship between the interior and interiority: That is, between the enclosure of physical space and the notion of subjectivity. There is a standard account which says that the two are deeply linked -that the articulation of interior space was part of what enabled the development of an initially bourgeois, decidedly European, notion of subjective life as being 政 account, wherein interiorior, rather than the interior. This is the theme I will pursue: That the standard account excludes a different way of thinking about interiority as being subjective experience and Interior Matters. A+T Publishers

20. Belén Hermida coins the term Urban Interior Design as part of the homonymous graduate degree in 2012, a joint venture between CEU Madrid "thiversity and Politecnico di Milano. As a subtitle, the master was defined as

21. Source: https://issuu.com/hwanroldan/docs/masterinurbanid

22. "The Primitive Hut has become a shorthand statement of principle that defines essential elements of architecture. Often, the phrase is "Laugier's Primitive Hut." Marc-Antoine Laugier (1713-1769) was a French Jesuit priest Source: ThoughtCo.

23. Interior Provocations symposium, Pratt Institute or publications like Interiors Without Architecture

24. "Instant City is a device made of moving objects (airships, tents, caps) and technology (cranes, refineries, robots) that seeps temporarily a community to create an audiovisual event. The architecture disappears in favor of a moving city in time and in space. It becomes an information network, education, entertainment and facilities for a population on the move. It demonstrates an impossible representation, that of a city that has no existence in itself, which is only an incident in time and in space. Instant City is a device made of moving objects (airships, tents, caps) and technology (cranes, refineries, robots) that seeps temporarily a community to create an audiovisual event. The architecture disappears in favor of a moving city in time and in space. It becomes an information network, education, entertainment and facilities for a population on the move. It demonstrates an impossible representation, that of a city that has no existence in itself, which is only an incident in time and in space." Peter Cook 1970.

\section{REFERENCES}

Merwood-Salisbury, Joanna and Vanessa Coxhead. "Exterior Interiors: the urban living room and beyond" in Interiors Beyond Architecture,
(Wiley, 2018) 139-152

Gage, Stephen. A suggested model for a-functional architecture. London: Taylor \& Francis, 2012

Ayres, Phil. Persistent Modelling: Extending the Role of Architectural Representation. Abingdon, Oxon England: Routledge, 2012

Rab, Samia. Shariah: Seascape Urbanism in a Khaliij Port City. Oxford: Oxford University Press, 2007.

Rudofsky, Architecture Without Architects: A Short Introduction to Non-Pedigreed Architecture. New York: MoMA Exhibition catalogue, 1964

Rossi, Aldo. The Architecture of the City. Padova: 1966

Cullen, Gordon. The Concise Townscape. Architectural Press, 1971

Atelier Bow Bow. Pet Architecture Guide Book. Tokio: World Photo Press, 2002

Perec, Georges. Species of Spaces and Other Pieces. London: Penguin Classics, 2008

Kayden, Jerold S.. PoPS: Privately Owned Public Space: The New York City Experience. New York: Wiley, 2000

John Chase, Margaret Crawford, John Kaliski. Everyday Urbanism. New York: Monacelli Press, 2008 